\title{
Structure and conduct of medicinal plants supply chain in Kwara State
}

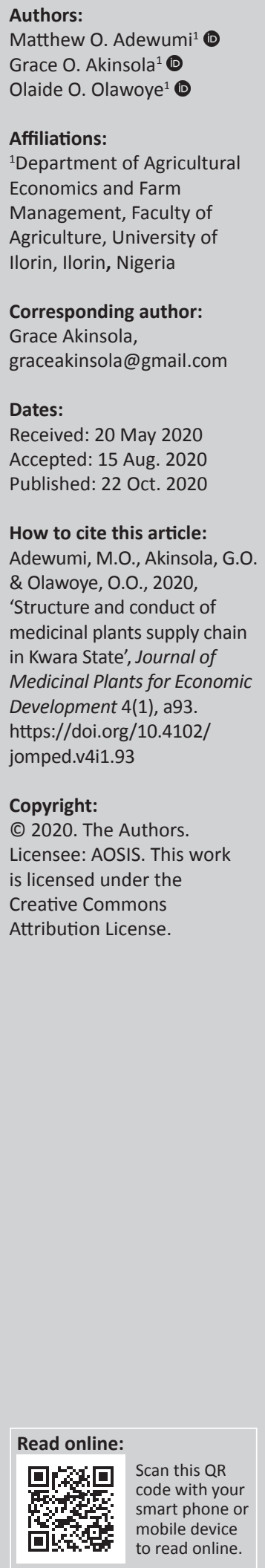

Background: There has been paucity of data on medicinal plants supply chain in Kwara State. The development of medicinal plants supply chain is a vital tool to ensure affordability and accessibility of medicinal plants to the herbal medicine producers.

Aim: This study examined the supply chain, structure, conduct and performance of medicinal plants in Kwara State.

Setting: Respondents data were drawn from the various sections of the herbal plants supply chain in Kwara State.

Methods: Descriptive statistics, concentration ratio, coefficient of variation, cost and returns analysis and Likert type scale were used for data analysis. Data collection was through interview schedule and structured questionnaire. Purposive and snowball sampling techniques were used to draw a sample of 128 respondents.

Results: The results revealed that the supply chain upstream was informal, and the chain is dominated by middle aged people. Four stages that existed on the supply chain included gatherers, farmers, herbal medicine producers and the final consumers. The highest supply source, which cut across all the actors in supply chain, was through gathering. This was followed by farmers. The least supply source was through importation. Farmers, gatherers and medicinal plant traders have non-concentrated market $(0.07,0.02$ and 0.09$)$, while Herbal Medicine (HM) producers had a moderately concentrated market (0.23). Binding prices, price regulation and barrier to entry and exit were inconspicuous. In general, the chain was adjudged to operate a fairly free market system. The enterprises were profitable with an average gross margin ratio of 0.76 for gatherers, 0.58 for farmers, 0.48 for traders and 0.46 for HM producers.

Conclusion: The study examined the structure and conduct of the medicinal plants chain in the study area, and the chain was adjudged to operate a fairly free market system.

Keywords: medicinal plants; market structure; supply chain; herbal medicine; Kwara State; Nigeria.

\section{Introduction}

Medicinal and aromatic plants (MAPs) are botanicals that provide people with medicines for different purposes including health maintenance, diseases prevention and remedying ailments. They also serve spiritual purposes, nutritional benefits and for toiletry and natural care. The use of medicinal plants for the health benefits of humans and animals has been in existence since ancient times according to the Department of Agriculture, Forestry and Fisheries (2016), while these medicinal plants are collected both from the wild and cultivated areas. Some of the primary end products of medicinal plants in Nigeria are traditionally prepared concoction and majorly and more recently herbal medicine. The growing popularity of herbal medicine (HM) originates from the need to meet the demand for essential medicine. Since the 1978 Alma Ata declaration on primary healthcare, which states that 'the provision of essential medicine is a vital and dominant part of primary healthcare', access to affordable essential medicine has become a topic of regular discourse (Obuaku 2014). Thirty per cent $(30 \%)$ of the world's population are estimated not to have proper access to essential medicine (EM) (WHO 2018). Affordability and perception seem to hinder the use of medicine.

The government organised many primary healthcare programmes. Some of which are: 'the revolving drug fund', Subsidy Reinvestment and Empowerment Programme - Maternal and Child Health (SURE-P MCH), The Strengthening Community Health and HIV Response Project (SCHHR) as well as the establishment of the National Primary Health Care Development Agency (NPHCDA) in 1992 (Obuaku 2014; Omonona et al. 2012). Use of medicinal and aromatic plants 
(MAP) which is seemingly affordable and readily acceptable to the populace of developing countries, especially rural dwellers, however, suffers from the issues of inappropriate dosage, unhygienic and substandard production. These issues, however, are overcome through herbal medicine (HM) production. According to Omonona et al. (2012), medicinal plants in Nigeria are now processed through modern means into capsules, tablets and syrups with accreditation from the National Agency for Food, Drugs Administration and Control (NAFDAC) which are referred to as herbal medicine. In the production of herbal medicine, MAPs, which are raw materials for HM production, can be acquired in different ways. Groot and Van Der Roest (2006) in describing the supply on medicinal plants asserted that firms that are fully integrated grow, extract and manufacture the whole product in-house and market the product, thus gaining full control over the quality of the products they sell. Other firms only carry out extraction and/or product development, whereas cultivation or collection of medicinal plants is outsourced; hence, there is diversity in the supply chain of medicinal and aromatic plants.

The two major sources of medicinal plants' abundant supply are cultivation and collection from the wild, the latter being the most important source in Nigeria. Plant parts such as barks, roots, stems, seeds and leaves are collected from wild species, and one third of such plants are trees, hence necessitating the conservation of trees FAO (Food and Agricultural Organization 2015a). In understanding the supply of medicinal plants for various purposes in Kwara State, which is the focus of this research, supply chain analysis was carried out. Supply chain encompasses all activities associated with moving and transforming inputs (goods) from the raw-materials stage through to the end user (Oburah, Ombok \& Omugah 2017). This is slightly different from value chain; value chain is a network of value adding activities carried out to move a product from conception, through sourcing of necessary inputs to production, processing and onward distribution to target market for consumption. Kumar et al. (2011) submitted that organising agricultural production along the value chain is a vital tool in bringing higher efficiency into agribusiness.

It is necessary to state that there are no sufficient research works on medicinal plants supply chain, as most have focused on the production and cultivation of medicinal plants, nutritional and health benefits, import and export of medicinal plants, excessive removal of endangered species as well as perception and utilisation of medicinal plants (DAFF 2016).

\section{Conceptual framework}

The structure and conduct aspects of the SCP (Structure, Conduct, Performance) framework were the premise for this analysis. According to Junior, Meuwissen and Lansink (2014), a dynamic SCP has been used to conceive strategies for firms by comparing their conducts along their business systems and inferring practices that yield highest performance. Fundamentally, in using the SCP framework to devise strategies, it is necessary to point out constructs or aspects of analysis for the purpose of this study which only included structure and conduct, called categories. The following can be considered in a value chain analysis: Structure (supply, demand, regulations, institutions, infrastructures, market concentration, entry barriers and rivalry intensity); Conduct (product, vertical linkages, horizontal linkages, distribution channels, pricing of input and output, source of raw material and product promotion strategies). The supply chain to a business man ordinarily means the steps it takes to get a product or service from its original state to the consumers. It is a network between a company and its suppliers to produce and distribute a specific product to the final buyer. Different activities, actors, entities, functions, information and inputs are covered under the supply chain. Different views of the supply chain mechanism exist in theory and practice; Oburah et al. (2017) submitted that supply chain may just be a virtual system. Yacine et al. (2009) described the supply chain as only a part of the value chain, stating that the value chain consists of the following in this order: design chain, supply chain and customer chain. According to them, the first general framework for SCM is the Supply Chain Reference Model (SCOR) which was developed by the Supply Chain Council. This model covers customer and market interactions and the physical material transactions; thus, it is said to be a general framework defining the supply chain standard processes and establishing standard terminology in quite broad terms. Hui (2008) reported that a supply chain is that network of organisations that are involved, through upstream and downstream linkages, in the different processes and activities that produce value in the form of products and services in the hands of the ultimate customer or consumer.

Supply chain can get divergent right from the beginning, for example, in medicinal plants, two major sources exist: cultivated and collected supplies. From another perspective, medicinal plants can be supplied fresh or dried; firms that use these plants may need them fresh, and hence, they go straight to the gatherers to get them making the supply chain shorter than the usual.

However, in some regions, it has been discovered that medicinal plants supply chain are quite long with up to six or seven different marketing stages that include primary gatherers, producers, local contractors, regional wholesale markets, large wholesale markets and specialised suppliers. This condition creates a problem in the chain; the primary problem being that gatherers and producers receive only a small share of the final consumers' fund (FAO 2015b).

\section{Aim and objectives}

Generally, this study sought to understudy the supply chain of medicinal plants in Kwara State. The specific objectives of the study were to:

- ascertain the types and sources of medicinal plants supplied

- describe the structure of the medicinal plants supply chain in Kwara State

- describe the conduct of the medicinal plants supply chain in the study area. 


\section{Research methods and design}

The study was carried out in Kwara State. The state cut across the southern guinea savannah and the derived savannah agro-ecological zones of Nigeria. The state has 16 local government areas with a population of 2371089 (National Population Commission 2006). The state has abundance of medicinal species such as Moringa, Mango, Baobab, Pipe vine, Enantia, Scent leaf and Nutmeg.

\section{Research approval}

The approval for the research was granted by the Department of Agricultural Economics and Farm Management of the University of Ilorin.

\section{Sampling}

Information on medicinal plants supply chain was drawn from 23 registered herbal medicine producers from Kwara State (Figure 1). The actors connected to modern herbal medicine producers were sampled using the snowball sampling technique. Through this technique, a total of 128 medicinal plants supply chain actors (respondents) were interviewed directly from the field survey using a structured questionnaire that serves as the source of primary data. The secondary information was collected from books, research reports and journals.

\section{Data analysis}

Descriptive statistics and concentration ratio were used in describing the data. The results were analysed using SPSS. The concentration ratio was used to describe the market structure and competitiveness of the herbal medicine market. The concentration ratio method used is the HerfindahlHirschman Index (HHI) (Equation 1) (Pindyck 2012). It is the sum of the squared market shares for all of the firms in the industry given as:

$$
\mathrm{HHI}=\sum_{i=1}^{m} S i^{2},
$$

Where $S i$ is the market share of firm $i$.

The values for HHI always lie between 0 and 1, that is, $0 \leq \mathrm{HHI} \leq 1$.

Where a value of:

$0=$ perfectly competitive industry

$1=$ monopoly

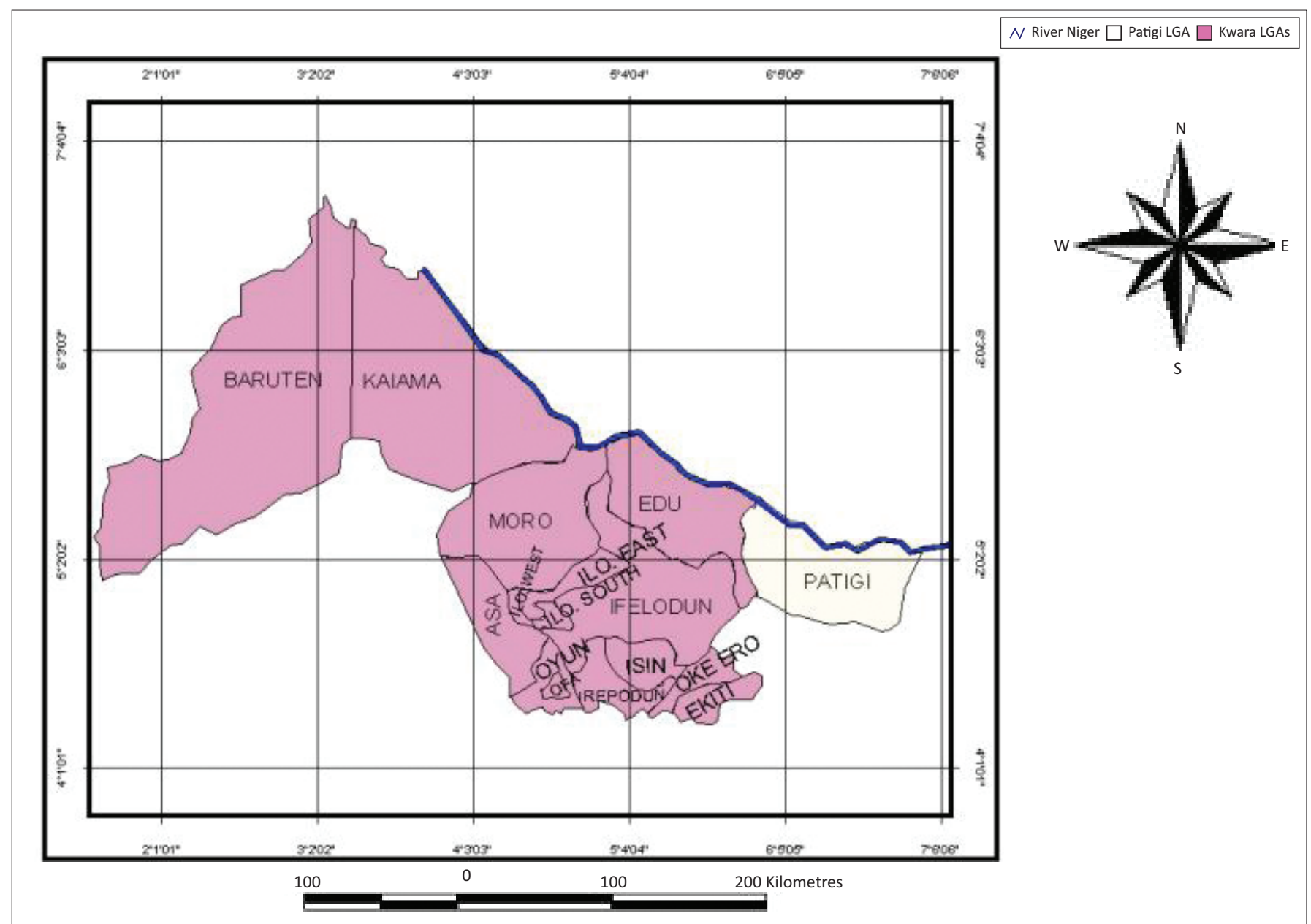

Source: Olabode, A., 2011, 'Determining rice productivity level for sustainable agricultural development in patigi local government area (Iga) of Kwara state, Nigeria', Journal of Sustainable Development in Africa 13, 125-135

LGAs, local government areas.

FIGURE 1: Map of Kwara State. 
Below 0.01 indicates a highly competitive industry Below 0.15 indicates a non-concentrated industry 0.15-0.25 indicates moderate concentration

Above 0.25 indicates high concentration

The analysis of the conduct of the medicinal plants supply chain was carried out using descriptive statistics, conventional mapping system and coefficient of variation. Descriptive statistics used includes frequency tables, measures of dispersion and central tendency. The conventional mapping system shows the vertical and horizontal linkages or interrelationship between different actors and the corresponding functions performed at different levels.

\section{Coefficient of variation}

The extent of the variation in prices paid by different modern herbal medicine producers for major medicinal plants used in producing modern herbal medicines was analysed in Equation 2 as follows:

Coefficient of variation $=\underline{\text { S.Di } \times 100}$

$\mathrm{Pa}$

[Eqn 2]

Where S.Di is the standard deviation of the $i$ th medicinal plant, and $\mathrm{Pa}$ is the average price of the medicinal plant.

\section{Ethical consideration}

Ethical clearance was not required for the study.

\section{Results and discussion Socioeconomic characteristics of actors}

The result of the study revealed that majority of the actors of the medicinal plants supply chain are men with fewer women. However, the medicinal plant trading is predominantly carried out by women $(93.8 \%)$ as against $6.2 \%$ men. The result is presented in Table 1 . This observation may be because this trading aspect does not require much physical strength as other sections of the chain. This observation is slightly different from the report of FAO (2015b) in Egypt where women rarely featured as major chain actors in the medicinal and aromatic plants chain but as suppliers of family labour during production on the farm and labourers at processing plants. The mean ages and years of experience are on the high side. The majority (97\%) of the actors interviewed were either married or widowed (Table 1); hence, it can be inferred that there is less participation of youths in the medicinal plant supply chain.

The result showed that large portion of the upstream actors have non-formal education, while down the chain, years of exposure to formal education tend to increase;

\begin{tabular}{|c|c|c|c|c|c|c|c|c|c|c|c|c|}
\hline \multirow[t]{2}{*}{$\begin{array}{l}\text { Socio-economic } \\
\text { characteristics }\end{array}$} & \multicolumn{2}{|c|}{ Farmers } & \multicolumn{2}{|c|}{ Gatherers } & \multicolumn{2}{|c|}{$\begin{array}{c}\text { Medicinal } \\
\text { plant traders }\end{array}$} & \multicolumn{2}{|c|}{ Agents } & \multicolumn{2}{|c|}{$\begin{array}{l}\text { Local concoction } \\
\text { makers }\end{array}$} & \multicolumn{2}{|c|}{ HM producers } \\
\hline & $n$ & $\%$ & $n$ & $\%$ & $n$ & $\%$ & $n$ & $\%$ & $n$ & $\%$ & $n$ & $\%$ \\
\hline \multicolumn{13}{|l|}{ Gender } \\
\hline Male & 11 & 64.7 & 47 & 79.7 & 1 & 6.2 & 2 & 100.0 & 1 & 10.0 & 18 & 78.3 \\
\hline Female & 06 & 35.3 & 12 & 20.3 & 15 & 93.8 & 0 & 0.0 & 9 & 90.0 & 5 & 21.7 \\
\hline Mean age (years) & 50 & - & 50 & - & 53 & - & 42 & - & 46 & - & 44 & - \\
\hline$<30$ years & 1 & 5.9 & 5 & 8.5 & 2 & 12.5 & 0 & 0.0 & 1 & 10.0 & 1 & 4.3 \\
\hline 30-39 years & 2 & 11.8 & 8 & 13.6 & 2 & 12.5 & 0 & 0.0 & 2 & 20.0 & 7 & 30.4 \\
\hline 40-49 years & 4 & 23.5 & 14 & 23.7 & 4 & 25.0 & 2 & 100.0 & 1 & 10.0 & 8 & 34.8 \\
\hline 50-59 years & 5 & 29.4 & 19 & 32.2 & 5 & 31.25 & 0 & 0.0 & 4 & 40.0 & 5 & 21.7 \\
\hline 60 and above & 5 & 29.4 & 13 & 22.0 & 3 & 18.6 & 0 & 0.0 & 2 & 20.0 & 2 & 8.7 \\
\hline \multicolumn{13}{|l|}{ Marital status } \\
\hline Single & 0 & 0.0 & 3 & 5.0 & 0 & 0.0 & 0 & 0.0 & 1 & 10.0 & 1 & 4.3 \\
\hline Married & 17 & 100.0 & 50 & 84.7 & 15 & 94.0 & 2 & 0.0 & 8 & 80.0 & 22 & 95.7 \\
\hline Others & 0 & 0.0 & 6 & 10.2 & 1 & 6.0 & 0 & 0.0 & 1 & 10.0 & 0 & 0.0 \\
\hline \multicolumn{13}{|l|}{ Religion } \\
\hline Islam & 17 & 100.0 & 46 & 78.0 & 16 & 100.0 & 1 & 50.0 & 6 & 60.0 & 17 & 74.0 \\
\hline Christianity & 0 & 0.0 & 10 & 16.9 & 0 & 0.0 & 1 & 50.0 & 3 & 30.0 & 5 & 21.7 \\
\hline Traditional & 0 & 0.0 & 3 & 5.1 & 0 & 0.0 & 0 & 0.0 & 1 & 10.0 & 1 & 4.3 \\
\hline Average years of experience & 18 & - & 21 & - & 35 & - & 16 & - & 17 & - & 11 & - \\
\hline $0-9$ years & 4 & 23.5 & 8 & 13.6 & 0 & 0.0 & 0 & 0.0 & 2 & 20.0 & 12 & 52.2 \\
\hline 10-19 years & 5 & 29.4 & 16 & 27.1 & 2 & 12.5 & 2 & 100.0 & 5 & 50.0 & 9 & 39.1 \\
\hline 20-29 years & 5 & 29.4 & 16 & 27.1 & 2 & 12.5 & 0 & 0.0 & 2 & 20.0 & 2 & 8.7 \\
\hline 30 years and above & 3 & 17.7 & 19 & 32.2 & 12 & 75.0 & 0 & 0.0 & 1 & 10.0 & 0 & 0.0 \\
\hline \multicolumn{13}{|l|}{ Education } \\
\hline Non-formal & 10 & 58.82 & 42 & 71.2 & 8 & 50.0 & 0 & 0.0 & 6 & 60.0 & 1 & 4.3 \\
\hline Formal & 07 & 41.18 & 17 & 28.8 & 8 & 50.0 & 2 & 100.0 & 4 & 40.0 & 22 & 95.7 \\
\hline Household size Average & 09 & - & 08 & - & 7 & - & 5 & - & 07 & - & 10 & - \\
\hline \multicolumn{13}{|l|}{ Membership of cooperative } \\
\hline Yes & 17 & 100.0 & 51 & 86.4 & 16 & 100.0 & 0 & 0.0 & 0 & 0.0 & 19 & 82.6 \\
\hline No & 0 & 0.0 & 8 & 13.6 & 6 & 0.0 & 2 & 100.0 & 10 & 100.0 & 4 & 17.4 \\
\hline
\end{tabular}

HM, herbal medicine.

Values in parenthesis are percentages. 
this result agrees with that of Mebrahtu, Zemede and Mirutse (2016) who submitted that the present medicinal value chain is characterised by a non-formal upstream base. This is likely because of the fact that gathering, which dominates the source of medicinal plant, does not require any special skill or education, and thus, it can be easily carried out by people who do not possess formal education.

\section{Results and discussion \\ Socioeconomic characteristics of actors}

Majority of the actors of the medicinal plant supply chain were men, although women were adequately represented (Table 1). However, the medicinal plant trading is predominantly carried out by women $(93.8 \%)$; this may be because this aspect does not involve much physical activities as other sections of the chain, and this is slightly different from the report of FAO (2015) in Egypt where women rarely featured as major chain actors in the medicinal and aromatic plants chain but as suppliers of family labour during production in the farms and labourers at processing plants. The mean ages and years of experience were on the high side, while the majority (97\%) of the actors interviewed were either married or widowed; hence, it can be inferred that there is less participation of youths in the medicinal plants supply chain, and younger people seldom subscribe to traditional medicine.

Large portion of the upstream actors have non-formal education, while down the chain years of exposure to formal education tend to increase; this result aligns with that of Mebrahtu et al. (2016) who submitted that the present medicinal value chain is characterised by an informal upstream base. This is likely because of the fact that gathering, which dominates the source of medicinal plant, does not require any special skill or education; thus, it can be easily carried out by people who do not possess formal education.

\section{Types of medicinal plants supplied}

The results from Table 2 revealed that farmers supply the annual and the biennial medicinal plants, as well as shrubs and trees, whereas gatherers supply barks and roots of large perennial shrubs and trees. From the result, it is evident that the most commonly supplied medicinal plants by cultivators are Scent leaf (Ocimum gratissimum), Moringa (Moringa oleifera) and Hyptis (Hyptis suaveolens), while Mango (Mangifera indica), Pattern wood (Alstonia boonei) and Neem tree (Azadirachta indica) are the commonly supplied plants by gatherers. This is because some of the most endemic diseases such as malaria and typhoid in the study area are treated with these three medicinal plants. Other highly supplied species were Pipe vine (Aristolochia macrophylla), Enantia (Enantia chlorantha), Byrsocarpus (Byrsocarpus coccineus) and Baobab (Adansonia digitata L.).
TABLE 2: Major types of medicinal plants supplied in the chain.

\begin{tabular}{llcc}
\hline Sources & Medicinal plants & Frequency & Percentage \\
\hline Farmers & Scent leaf (Ocimum gratissimum) & $12^{\mathrm{a}}$ & 70.59 \\
& Moringa (Moringa oleifera) & $8^{\mathrm{b}}$ & 47.06 \\
& Pignut (Hyptis suaveolens) & $7^{\mathrm{c}}$ & 41.18 \\
& Pawpaw (Carica papaya) & $4^{\mathrm{e}}$ & 23.53 \\
& Lime (Citrus aurantiifolia) & $5^{\mathrm{d}}$ & 29.41 \\
& Bitter leaf (Vernonia amygdalina) & $5^{\mathrm{d}}$ & 29.41 \\
Gatherers & Mango (Mangifera indica) & $36^{\mathrm{a}}$ & 61.02 \\
& Pattern wood (Alstonia boonei) & $34^{\mathrm{b}}$ & 57.63 \\
& Enantia (Enantia chlorantha) & $25^{\mathrm{e}}$ & 42.37 \\
& Byrsocarpus (Byrsocarpus coccineus) & $24^{\mathrm{f}}$ & 40.68 \\
& Baobab (Adansonia digitata L.) & $23^{\mathrm{g}}$ & 38.98 \\
Gum Arabic (Acacia senegal) & $17^{\mathrm{j}}$ & 28.81 \\
& African peach (Kiggelaria africana) & $20^{\mathrm{j}}$ & 33.90 \\
& Mulberry (Morus nigra) & $23^{\mathrm{g}}$ & 38.98 \\
& Neem tree (Azadirachta indica) & $32^{\mathrm{c}}$ & 54.24 \\
Bois de Rose (Cordia alliodora) & $17^{\mathrm{j}}$ & 28.81 \\
Golden shower tree (Cassia fistula) & $15^{\mathrm{k}}$ & 25.42 \\
Pipe vine (Aristolochia macrophylla) & $29^{\mathrm{d}}$ & 49.15 \\
Bitter melon (Mormodica charantia) & $11^{\mathrm{j}}$ & 18.64 \\
African mahogany (Khaya senegalensis) & $21^{\mathrm{h}}$ & 35.59 \\
\hline & Black seed (Nigella sativa) & 2 & 100.00 \\
Hulba (Trigonella foenum-graecum) & 1 & 50.00 \\
Olive (Olea europaea) & 2 & 100.00 \\
\hline
\end{tabular}

Note: The superscript alphabets show the ranking of the medicinal plants based on the level of their supply.

Scientific names are in parenthesis.

$\dagger$, Multiple responses.

TABLE 3: Sources of medicinal plants.

\begin{tabular}{llcc}
\hline Other chain actors & Sources & Frequency $\dagger$ & Percentage \\
\hline Medicinal plant & Cultivation (Farmers) & 9 & 56.25 \\
traders & Gatherers & 16 & 100.00 \\
Herbal medicine & Cultivation (Farmers) & 17 & 73.91 \\
producers & Gatherers & 22 & 95.65 \\
& Importation & 3 & 13.04 \\
Local concoction & Cultivation (Farmers) & 10 & 100.00 \\
& Gatherers & 10 & 100.00 \\
Agents & Cultivation (Farmers) & 1 & 50.00 \\
& Gatherers & 2 & 100.00 \\
& Importation & 2 & 100.00 \\
\hline
\end{tabular}

$\dagger$, Multiple responses.

\section{Sources of medicinal plants supplied}

The major sources of medicinal plant supplied within the chain in Kwara State are cultivation (farmers), gathering and importation as shown in Table 3. All the secondary actors of the chain got medicinal plants from gatherers and cultivators $(100 \%)$, while only two bought small amount of medicinal plants through importation. Majority of the medicinal and aromatic plants supplied into the chain in Kwara State are sourced by gatherers, followed by cultivation and the least source being importation; this is in line with the findings of DAFF (2016), where it reported that medicinal plants were indiscriminately removed from the wild by gatherers being the major source of MAPs supplied into the market. Gatherers supply a long list of medicinal plants once there is demand for it; major parts of the medicinal plants supplied include barks, leaves, pods, roots and stems. It is recommended that gatherers and those who supply unskilled labour for the gathering activities should be enlightened through formation of association, use of mass media, regular town meetings and 
strict regulations on the need to replant trees and use less destructive means in tree harvesting to ensure sustainable use of forest resources.

\section{The structure of the medicinal plant supply chain}

This section shows the result and interpretation of the structure of the medicinal plant supply chain in the study area. Subject matters reported include the accessibility of infrastructure to the chain actors, market concentration, product differentiation, conditions of entry and exit into the market, forms of supply and regulations to business activities.

Table 4 shows the market concentration analysis. It can be deduced that a healthy level of competition exists in the various stages of the major chain actors as all $\mathrm{HHI}$ values were less than $25 \%$. Gatherers (2.02\%) have the least score which means that at the level of these actors, the market is close to ideal in competition; this may be because they all use the same inputs and similar skill level for their gathering processes and are unlikely to outwit others in their outputs. The situation is not too different for farmers $(7.02 \%)$ and medicinal plant traders $(9.16 \%)$ with values still clearly less than the $15 \%$ threshold for non-concentrated market.

However, for the HM producers (23.69\%), monopolistic tendencies tend to be present as the concentration level of the market moved from non-concentration to moderate concentration downstream. The implication is that a few firms are producing much more than the others, and thus, they have a larger share of the market. The reasons for this based on this study is largely because of the fact that some $\mathrm{HM}$ producers have access to large amount of raw material

TABLE 4: Market concentration

\begin{tabular}{lcccl}
\hline Actors & Frequency & $\begin{array}{c}\text { HHI } \\
\text { score }\end{array}$ & $\begin{array}{c}\text { Percentage } \\
\text { score of HHI }\end{array}$ & Remark \\
\hline Farmers & 17 & 0.0702 & 7.02 & Non-concentrated market \\
Gatherers & 59 & 0.0202 & 2.02 & Non-concentrated market \\
Medicinal plant traders & 16 & 0.0916 & 9.16 & Non-concentrated market \\
HM producers & 23 & 0.2369 & 23.69 & Moderate concentration \\
\hline
\end{tabular}

$\mathrm{HHI}$, Herfindahl-Hirschman Index; HM, herbal medicine. and huge capital base; hence, they use advanced technology. They also have long years of experience and possess political connections. All these enable them to produce in high proportion. A higher HHI index for the HM producers, which is as a result of some firms having larger shares of the market, can lead to minor fluctuations in price of herbal medicine, affect overall supply of medicinal plants into the chain as well as reduce consumer surplus and economic welfare.

Table 5 shows the result of other variables captured under the structure of the supply chain of medicinal plants in the study area. Product differentiation is relatively absent with the actors except HM producers, where the majority (95.7\%) submitted that their products are different from that of others. Differentiation factors include the product packaging, scope of effectiveness and secret ingredients that are apparently spiritual.

Barriers to entry were reported only by medicinal plant traders $(37.5 \%)$ and HM producers $(100 \%)$; this is true as sometimes the traders need to go through apprenticeship before they can fully participate in trading on these plants, while others said it was family business, and hence, they inherited the trade. For HM producers, a barrier abounds to starting the business in the state as they must belong to the Herbal Medicine Association in the State, go through some registrations stipulated by the Ministry of Health and undergo NAFDAC screening for their products. However, business regulation was only and fully (100\%) recorded for the HM producers.

The forms of supply across the chain are majorly local for farmers, gatherers and medicinal plant traders; this is because most of them are low-income earners and are not able to afford the cost of exportation and the cost of processing medicinal plants into exportable forms; $47.8 \%$ of the HM producers carry out the international supply of both finished products and sometimes grounded and well-packaged medicinal plants, although this aligns with the findings of DAFF (2016), but it was added in their report that raw roots and barks are also exported.

TABLE 5: Other elements of the chain structure.

\begin{tabular}{|c|c|c|c|c|c|c|c|c|c|c|}
\hline \multirow[t]{2}{*}{ Variables } & \multicolumn{2}{|c|}{ Farmers } & \multicolumn{2}{|c|}{ Gatherers } & \multicolumn{2}{|c|}{ Medicinal plant traders } & \multicolumn{2}{|c|}{ Concoction } & \multicolumn{2}{|c|}{ HM producers } \\
\hline & $n$ & $\%$ & $n$ & $\%$ & $n$ & $\%$ & $n$ & $\%$ & $n$ & $\%$ \\
\hline \multicolumn{11}{|c|}{ Product differentiation } \\
\hline Yes & 02 & 11.8 & 01 & 1.6 & 0 & 0.0 & 10 & 100.0 & 22 & 95.7 \\
\hline No & 15 & 88.2 & 58 & 98.4 & 16 & 100.0 & 0 & 0.0 & 01 & 4.3 \\
\hline \multicolumn{11}{|c|}{ Barrier to entry/exit } \\
\hline Yes & 0 & 0.0 & 0 & 0.0 & 06 & 37.5 & 0 & 0.0 & 23 & 100.0 \\
\hline No & 17 & 100.0 & 59 & 100.0 & 10 & 62.5 & 10 & 100.0 & 0 & 0.0 \\
\hline \multicolumn{11}{|c|}{ Regulation to business } \\
\hline Yes & 0 & 0.0 & 0 & 0.0 & 0 & 0.0 & 0 & 0.0 & 23 & 100.0 \\
\hline No & 17 & 100.0 & 59 & 100.0 & 16 & 100.0 & 10 & 100.0 & 0 & 0.0 \\
\hline \multicolumn{11}{|c|}{ Forms of supply $\dagger$} \\
\hline Global & 1 & 5.9 & 2 & 3.4 & 4 & 25.0 & 0 & 0.0 & 11 & 47.8 \\
\hline Local & 17 & 100.0 & 59 & 100.0 & 16 & 100.0 & 10 & 100.0 & 23 & 100.0 \\
\hline
\end{tabular}

HM, herbal medicine.

$\dagger$, Multiple responses. 
Table 6 revealed that throughout the chain, accessibility to infrastructure lies majorly on the upper ends of the scale being easily accessible and fairly accessible. Water and health services have the highest scores; rain water alone can sustain medicinal plant growth, while herbal medicine producers all have boreholes within their facilities. Health service is high probably because these actors are also participating in health sector; hence, they can readily access traditional and allopathic medicine made available through the chain. Electricity and communication facility have the least scores of 2.2; electricity supply in the state is epileptic which conforms to the findings of Ajao et al. (2009), a situation that mostly affects the herbal medicine producers.

\section{Conduct of the supply chain}

This section was designed to analyse, report and discuss the conduct of the medicinal plant supply chain in Kwara State. The section assessed the functions performed by actors, the existence of binding prices across the chain, price variation of the most common medicinal plants, knowledge of prices, vertical linkages and horizontal linkages.

Table 7 reveals the results of some important variables of the supply chain conduct; prices are not binding in the chain neither are they regulated by the actors or any external body, although there are business regulations for the HM producers but this does not include price setting. Knowledge of prices is also relatively high in the market; hence, it can be inferred that the market is a competitive market.

TABLE 6: Accessibility to infrastructure throughout the chain.

\begin{tabular}{lccl}
\hline Infrastructure & Aggregate score & Average score & Remark \\
\hline Water & 359 & 3.1 & Easily accessible \\
Good building & 311 & 2.7 & Fairly accessible \\
Electricity & 255 & 2.2 & Fairly accessible \\
Transportation & 308 & 2.7 & Fairly accessible \\
Health services & 358 & 3.1 & Easily accessible \\
Market & 335 & 2.9 & Fairly accessible \\
Communication facility & 258 & 2.2 & Fairly accessible \\
Education & 310 & 2.7 & Fairly accessible \\
\hline
\end{tabular}

Note: Accessibility ranked on a scale of 4 points.
A conduct of the chain which concerns only the gatherers is the replanting of trees; all the gatherers (100\%) interviewed does not carry out replanting activities, especially of trees whose roots are harvested for sale. This may be because of their ignorance of the significance of this fact or for the abundance of these species in the forest. The implication is that heavily supplied medicinal species will continue to deplete in the forest and may be at risk of becoming very rare or extinct in the state; non-replanting of harvested medicinal plant species is also recorded in Ashish and Jnanesha (2015) and DAFF (2016).

\section{Price variation}

This was carried out using the coefficient of variation to ascertain if there are significant differences in the prices paid for similar materials by different actors within the chain. Table 8 shows the coefficient of variation in price of the three most supplied medicinal plants by gatherers, while Table 9 shows the coefficient of variation in the prices of the most supplied medicinal plants by farmers.

Table 8 depicts the variation in the unit selling prices of the most supplied medicinal plants with an average of $13.14 \%$, although knowledge of prices at the level of the gatherers is prevalent, but as there are neither price regulations nor binding price as reported in Table 8, gatherers may decide to sell at a higher or lower price depending on who they supply their medicinal plants. Gatherers who have their spouses or parents doing the medicinal plant trading at the local market may give it to them at lower prices than those selling to strangers. Another reason for the price disparity although minimal may be because some gatherers sell directly to HM producers; hence, they sell at a price equal or close to that of medicinal plant traders.

Table 9 shows the price variation in the unit selling prices of the most supplied medicinal plants by farmers with an average of $6.63 \%$, which is lower than that of the gatherers.

TABLE 8: Coefficient of variation in prices (gatherers).

\begin{tabular}{lccc}
\hline Medicinal plants & Standard deviation & $\begin{array}{c}\text { Coefficient of } \\
\text { variation (CV) }\end{array}$ & Percentage CV \\
\hline Mango & 316.49 & 0.1329 & 13.29 \\
Pattern wood & 420.71 & 0.1171 & 11.71 \\
Neem tree & 407.31 & 0.1444 & 14.44 \\
\hline
\end{tabular}

TABLE 7: Conduct of the supply chain.

\begin{tabular}{|c|c|c|c|c|c|c|c|c|c|c|}
\hline \multirow[t]{2}{*}{ Variables } & \multicolumn{2}{|c|}{ Farmers } & \multicolumn{2}{|c|}{ Gatherers } & \multicolumn{2}{|c|}{ Medicinal plant traders } & \multicolumn{2}{|c|}{ Concoction } & \multicolumn{2}{|c|}{ HM producers } \\
\hline & $n$ & $\%$ & $n$ & $\%$ & $n$ & $\%$ & $n$ & $\%$ & $n$ & $\%$ \\
\hline \multicolumn{11}{|c|}{ Binding price } \\
\hline Yes & 0 & 0.0 & 0 & 0.0 & 0 & 0.0 & 0 & 0.0 & 0 & 0.0 \\
\hline No & 17 & 100.0 & 59 & 100.0 & 16 & 100.0 & 10 & 100.0 & 23 & 100.0 \\
\hline \multicolumn{11}{|c|}{ Knowledge of price } \\
\hline Yes & 13 & 76.5 & 56 & 100.0 & 05 & 31.25 & 02 & 20.0 & 07 & 30.4 \\
\hline \multicolumn{11}{|c|}{ Price regulation } \\
\hline Yes & 0 & 0.0 & 0 & 0.0 & 0 & 0.0 & 0 & 0.0 & 0 & 0.0 \\
\hline No & 17 & 100.0 & 59 & 100.0 & 16 & 100.0 & 10 & 100.0 & 23 & 100.0 \\
\hline \multicolumn{11}{|c|}{ Replanting of trees } \\
\hline Yes & - & - & 0 & 0.0 & - & - & - & - & - & - \\
\hline No & - & - & 59 & 100.0 & - & - & - & - & - & - \\
\hline
\end{tabular}

HM, herbal medicine. 
TABLE 9: Coefficient of variation in prices (farmers).

\begin{tabular}{lccc}
\hline Medicinal plants & Standard deviation & $\begin{array}{c}\text { Coefficient of } \\
\text { variation (CV) }\end{array}$ & Percentage CV \\
\hline Scent leaf & 157.15 & 0.0529 & 5.30 \\
Moringa & 395.51 & 0.1076 & 10.76 \\
Hyptis & 109.65 & 0.0384 & 3.84 \\
\hline
\end{tabular}

Note: Linkages between actors of the medicinal plant supply chain in Kwara State.

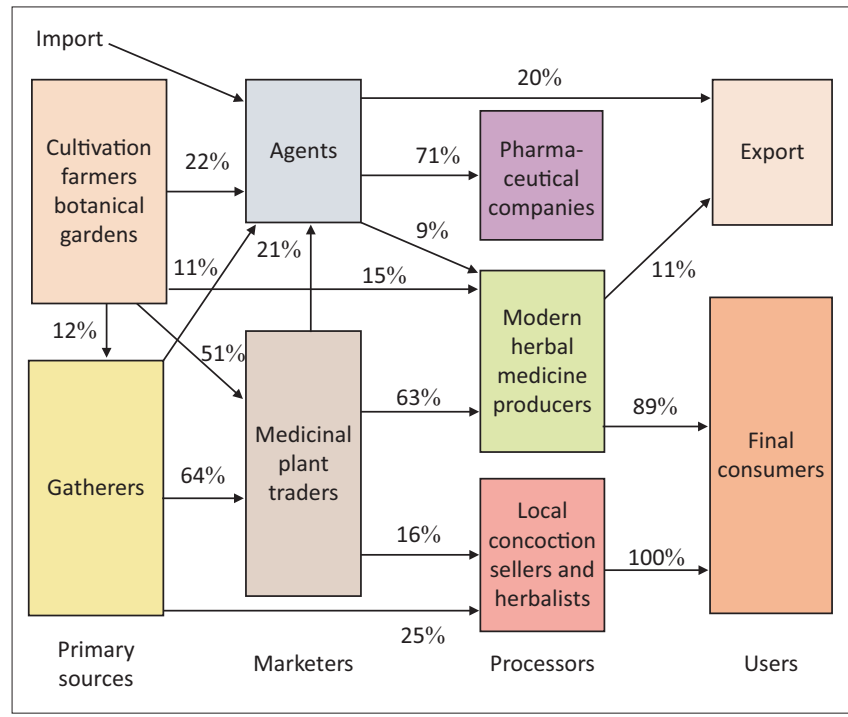

FIGURE 2: Supply chain of medicinal plants in Kwara State.

The plant with a relatively high variation coefficient is Moringa (10.76\%); the variation is majorly because of differences in the level of value adding activities carried out by different Moringa farmers on their products such as drying, sorting, grinding inter alia. The higher the value addition, the higher the selling price of such medicinal plants.

Figure 2 depicts the channel of supply of the medicinal plants in the supply chain; this is connected with the analysis on Table 3. The linkage is segmented into four sections:

- Section 1 (Gatherers, cultivators and import);

- Section 2 (Medicinal plant traders and agents);

- Section 3 (Local concoction sellers and herbalists, HM producers and pharmaceutical companies)

- Section 4 (Final consumers and export)

The horizontal relationship between the different sections is not only sequential as there are overlapping relationships between Sections 'Gatherers, cultivators and import' and 'Local concoction sellers and herbalists, herbal medicine producers and pharmaceutical companies' as well as Sections 'Medicinal plant traders and agents' and 'Final consumers and export'. Apart from the vertical linkages from upstream down the stream, horizontal linkages also exist, especially in the first and second sections, as gatherers sometimes get supplies from cultivators, while agents also buy from medicinal plant traders.

\section{Conclusion}

This study tends to establish that a functional, fairly organised supply chain exists for medicinal plants in Kwara
State of Nigeria. In addition, the nature of the market from the study of the structure and conduct indicated, to a large extent, a competitive market that operates freely but with a few anomalies. Finally, the chain is functioning appropriately; however, better result is possible if the chain is better structured.

\section{Acknowledgements Competing interests}

The authors have declared that no competing interests exist.

\section{Authors' contributions}

All authors contributed equally to this work.

\section{Funding information}

This research received no specific grant from any funding agency in the public, commercial or not-for-profit sectors.

\section{Data availability statement}

Data sharing is not applicable to this article.

\section{Disclaimer}

The views and opinions expressed in this article are those of the authors and do not necessarily reflect the official policy or position of any affiliated agency of the authors.

\section{References}

Abiodun, O., 2011, 'Determining rice productivity level for sustainable agricultural development in patigi local government area (LGA) of Kwara State, Nigeria', Journal of Sustainable Development in Africa 13, 125-135.

Ajao, K.R., Ajimotokan, H.A., Popoola, T. \& Akande, H., 2009, 'Electric energy supply in Nigeria, decentralized energy approach', Cogeneration and Distributed Generation Journal 24(4), 34-50. https://doi.org/10.1080/15453660909595149

Ashish, K. \& Jnanesha, A.C., 2015, 'Conservation of rare and endangered plant species for medicinal use', International Journal of Science and Research 5(12), 1370-1372.

Department of Agriculture, Forestry and Fisheries, 2016, A profile of the South African medicinal plants market value chain, viewed 10 November 2018, from https://www.daff.gov.za

Food and Agricultural Organization, 2015a, Trade in medicinal plants, Food and Agricultural Organization, Rome.

Food and Agricultural Organization, 2015b, Gender sensitive value chain analysis for medicinal and aromatic plants in Fayoum by North South Consultants Exchange, Food and Agricultural Organization, Rome.

Groot, M. \& Van Der Roest, J., 2006, 'Quality control in the production chain of herbal product', in R.J. Bogers, L.E. Craker \& D. Lange (eds.), Medicinal and aromatic plants, pp. 253-260, Springer, Netherlands.

Hui, N.A.Y., 2008, 'Supply chain model for rice in Malaysia - Basics and challenges', ECER regional conference, 2008, Malaysia.

Junior, H.S., Meuwissen, M.P.M. \& Lansink, A.G.J.M., 2014, 'Integrating structure, conduct and performance into value chain analysis', Journal on Chain and Network Science 14(1), 21-30. https://doi.org/10.3920/JCNS2014.0231

Kumar, A., Singha, H., Kumar, S. \& Mittalb, S., 2011, 'Value chains of agricultural commodities and their role in food security and poverty alleviation - A synthesis', Agricultural Economics Research Review 24(1), 169-181. https://doi.org/ 10.22004/ag.econ.109516

Mebrahtu, H., Zemede, A. \& Mirutse, G., 2016, 'Review on value chain analysis of medicinal plants and the associated challenges', Journal of Medicinal Plants Studies 4(3), 45-55.

National Population Commission, 2006, 'Report of Nigeria's national population commission on the 2006 census', Population and Development Review 33(1), 206-210.

Obuaku, C., 2014, 'Essential medicines in Nigeria: Foregrounding access to affordable essential medicines', African Sociological Review 18(2), 42-60. 
Oburah, J., Ombok, B.O. \& Omugah, G., 2017, 'Analysis of rice supply chain in Kenya', International Journal of Managerial Studies and Research (IJMSR) 5(8), 12-17. https://doi.org/10.20431/2349-0349.0508002

Olabode, A., 2011, 'Determining rice productivity level for sustainable agricultural development in patigi local government area (Iga) of Kwara state, Nigeria', Journal of Sustainable Development in Africa 13, 125-135.

Omonona, B.T., Egbetokun, O.A., Ajijola, S. \& Salaam, A.H., 2012, 'Consumer preference for medicinal plants in Oyo Metropolis, Nigeria', Journal of Medicinal Plants Research 6(20), 3609-3613. https://doi.org/10.5897/JMPR11.1119
Pindyck, R.S., 2012, Lecture notes on Market definition and concentration, Sloan School of Management - Massachusetts Institute of Technology, Boston, MA.

World Health Organization, 2018, Access to medicines: Making market forces serve the poor, WHO, Geneva.

Yacine, O., Matteo, M.S., Abdelaziz, B. \& Carlo, D.D., 2009, 'Supply chain management analysis: A simulation approach of the Value Chain Operations Reference model (VCOR)', International Journal of Value Chain Management 3(3), 263-287. https:// doi.org/10.1504/IJVCM.2009.028603 